\title{
Features of Vibration of Ship Generator Caused by Coupling Effect of Load Fluctuation
}

\author{
Hanlin Li, ${ }^{1,2}$ Hongliang Yu, ${ }^{1,2 *}$ Wanneng Yu, ${ }^{1,2}$ Shilun Huang, ${ }^{1,2}$ \\ Jianbin Liao, ${ }^{1,2}$ Jin Yan, ${ }^{1,2}$ and Chih-Cheng Chen ${ }^{1,3 *}$ \\ ${ }^{1}$ Jimei University, Xiamen 361021, China \\ ${ }^{2}$ Fujian Provincial Key Laboratory of Naval Architecture and Ocean Engineering, Xiamen 361021, China \\ ${ }^{3}$ Department of Industrial Engineering and Management, Chaoyang University of Technology, \\ Taichung 413310, Taiwan
}

(Received July 20, 2020; accepted November 25, 2020)

Keywords: generator, load, vibration, acceleration sensor

The large-capacity changes of the resistive and inductive loads of a ship generator at the same time will have a coupling effect on its vibration. To study the coupling mechanism of electromagnetic vibration caused by the radial electromagnetic force of a generator under different loads, we lay a theoretical foundation for the solution of controlling generator coupling vibration. A finite element analysis method is used to build a simulation calculation model of the generator, and changes in the external load are simulated by changing the external circuit diagram. Using several acceleration sensors, we test the vibration response of the generator, analyze the experimental data, and verify the correctness of the theoretical analysis under different load conditions.

\section{Introduction}

Synchronous generators provide usable and stable power output for ships. Internal electromagnetic vibration is one of the main sources of generator vibration. The switching of the size and nature of the electrical load during the operation of a ship will cause the internal magnetic field of the generator to change, which can have different effects on the vibration of the generator. ${ }^{(1)}$ In particular, when the resistive load and the inductive load change at the same time, it will have a coupling effect on the vibration of the generator, which makes it difficult to judge the change rule of the vibration signal. Su et al. used the finite element method to study the influence of different slot magnetic wedges and different slot indices on the electromagnetic excitation force of a motor. ${ }^{(2)}$ Zhang et al. performed vibration relationship simulations with different base installation methods, material stiffnesses, and structural damping and compared the results. The motor operation method was used to test the vibration acceleration of the base feet of the generator. ${ }^{(3)}$ Liu et al. explored the causes of vibration noise generated by synchronous generators from a control perspective, and proposed some effective algorithms to reduce motor vibration noise. ${ }^{(4)}$ Ellison and Moore found that low-power motors are not greatly affected by load changes, possibly because the excitation frequency is much lower than the *Corresponding author: e-mail: yu1202@hotmail.com ** Corresponding author: e-mail: 201761000018@jmu.edu.cn https://doi.org/10.18494/SAM.2021.3036 
resonance frequency of the motor itself. ${ }^{(5)}$ Brozek found that the load has a significant effect on motor noise. ${ }^{(6)}$ Kako studied the noise of induction motors under different loads and found that the noise increased with the load. ${ }^{(7)}$ Most of the above research focused on simulation, and there has been little research on the coupled vibration of a generator caused by changes in resistive and inductive loads. ${ }^{(8-11)}$ Therefore, the novelty of this paper is that theoretical analysis, modeling and simulation, and an experiment with acceleration sensors are performed to study the coupling mechanism between the changes in load and vibration of a generator to provide a theoretical basis for the vibration reduction of a ship generator.

\section{Finite Element Analysis of the Electromagnetic Force of a Generator}

\subsection{Analysis of generator air gap magnetic field}

The electromagnetic field of a generator is weakly coupled with its structure. To solve the vibration response model, the finite element method combining the electromagnetic field and stress field is used. The main parameters of the synchronous generator are shown in Table 1.

Figure 1 shows the distribution of the magnetic field lines in the finite element analysis. The graph represents the working condition of the generator under no load with a speed of 1500 $\mathrm{rpm}$. It can be seen from the figure that the magnetic lines of the force at the air gap mostly enter the stator teeth in the radial direction, the magnetic density is mainly concentrated in the teeth of the stator, and the magnetic density under each pair of poles changes periodically.

Table 1

Main parameters of synchronous generator.

\begin{tabular}{lccc}
\hline Rotor position & Inner rotor & Rotor outer diameter & $97.5 \mathrm{~mm}$ \\
Stator inner diameter & $98 \mathrm{~mm}$ & Stator outer diameter & $155 \mathrm{~mm}$ \\
Phase & 3 & Number of pole pairs & 2 \\
Rated voltage & $400 \mathrm{~V}$ & Rated output power & $2 \mathrm{~kW}$ \\
Number of slots & 36 & Rated speed & $1500 \mathrm{rpm}$ \\
\hline
\end{tabular}

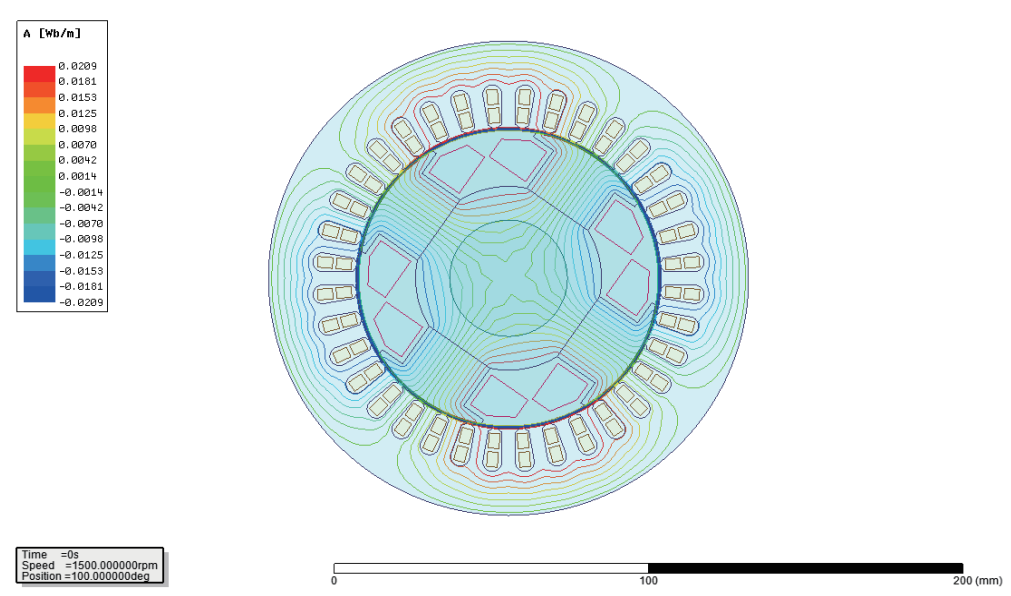

Fig. 1. (Color online) Distribution of magnetic field lines. 
The generator is driven by the prime mover to convert mechanical energy into electrical energy in the form of electromagnetic energy. The electromagnetic force in the air gap of a generator $F_{r}$ is commonly calculated by the Maxwell tensor method:

$$
F_{r}=\frac{B_{r}^{2}-B_{n}^{2}}{2 \mu_{0}}
$$

As can be seen from the above formula, to calculate the electromagnetic force inside the generator, the radial magnetic density and the tangential magnetic density inside the generator need to be obtained. The radial air gap magnetic density is given by Eq. (2) and the tangential air gap magnetic density is given by Eq. (3).

$$
\begin{aligned}
& B_{r}=B_{y} \cos (\theta)+B_{x} \sin (\theta) \\
& B_{t}=B_{y} \cos (\theta)-B_{x} \sin (\theta)
\end{aligned}
$$

Figure 2 shows the external circuit diagram of the generator used to simulate the electromagnetic force in the generator under a resistive load. Table 2 gives the magnetic density in the air gap of the generator at $t=0.1 \mathrm{~s}$. With the increase in inductive load, that is, the increase in reactive power, regardless of whether magnetization or demagnetization occurs, the air gap magnetic density of the generator will increase, and the electromagnetic force of the generator will increase, which will increase the vibration of the generator.

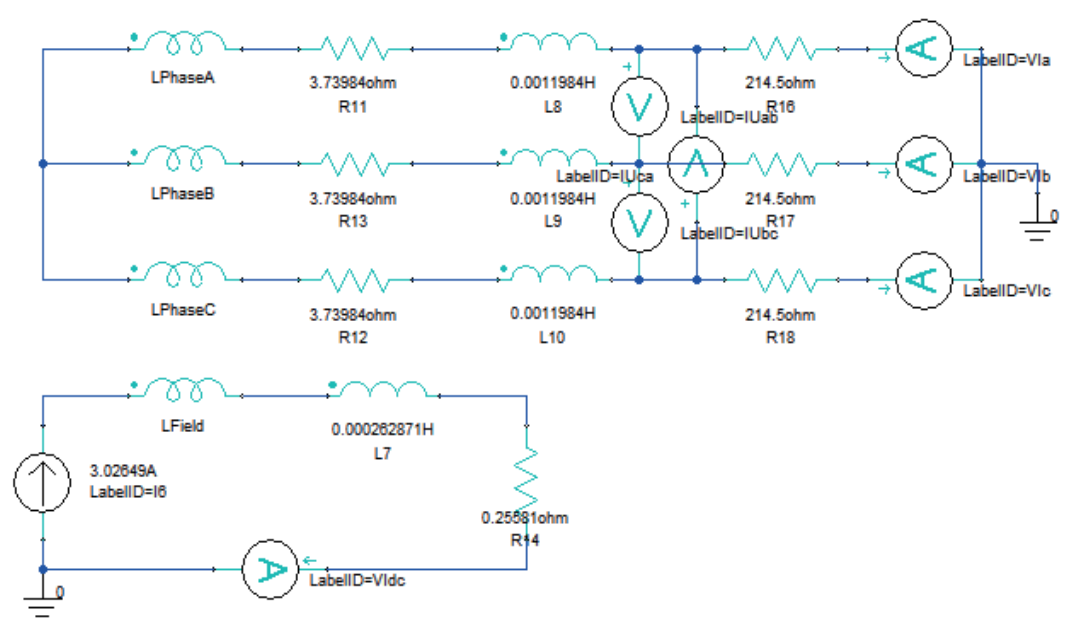

Fig. 2. (Color online) External circuit diagram of synchronous generator.

Table 2

Air gap magnetic density under inductive load.

\begin{tabular}{lcccccc}
\hline Inductive load $(\Omega)$ & 50 & 100 & 150 & 200 & 250 & 300 \\
\hline Air gap magnetic density $(\mathrm{T})$ & 0.5447 & 0.5462 & 0.5475 & 0.5483 & 0.5485 & 0.5493 \\
\hline
\end{tabular}




\subsection{Solving electromagnetic force}

The radial and tangential electromagnetic force density waveforms of the synchronous generator are shown in Figs. 3 and 4, respectively. It can be seen from the two figures that the value of the radial electromagnetic force waveform of the generator is 2-3 times that of the tangential waveform, and the main cause of the generator vibration response is the radial electromagnetic force. It can also be seen that the radial electromagnetic force density waveform and the tangential density waveform of the synchronous generator have the same period and the same sinusoidal trend.

\section{Vibration Test Experiment}

\subsection{Experiment on generator vibration}

The platform with the motor used in our simulation-based experiment is shown in Fig. 5. The platform is composed of a motor, generator, connecting shaft, control cabinet, inductance,

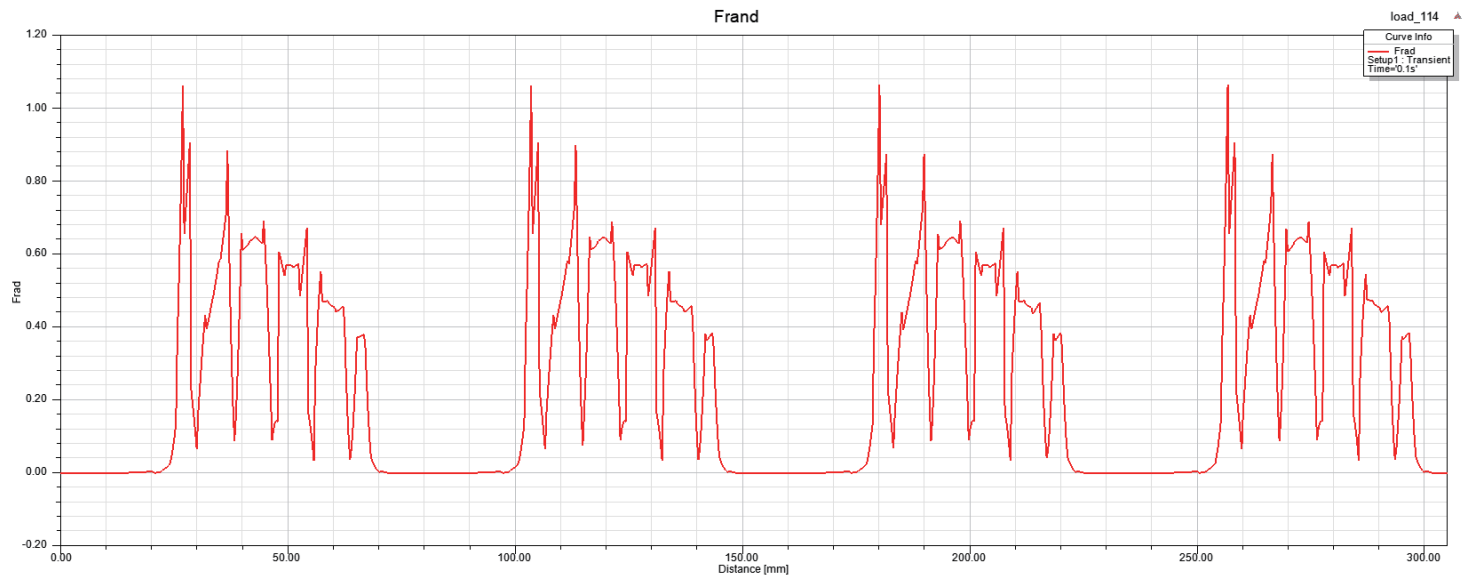

Fig. 3. (Color online) Waveform of radial electromagnetic force density of synchronous generator.

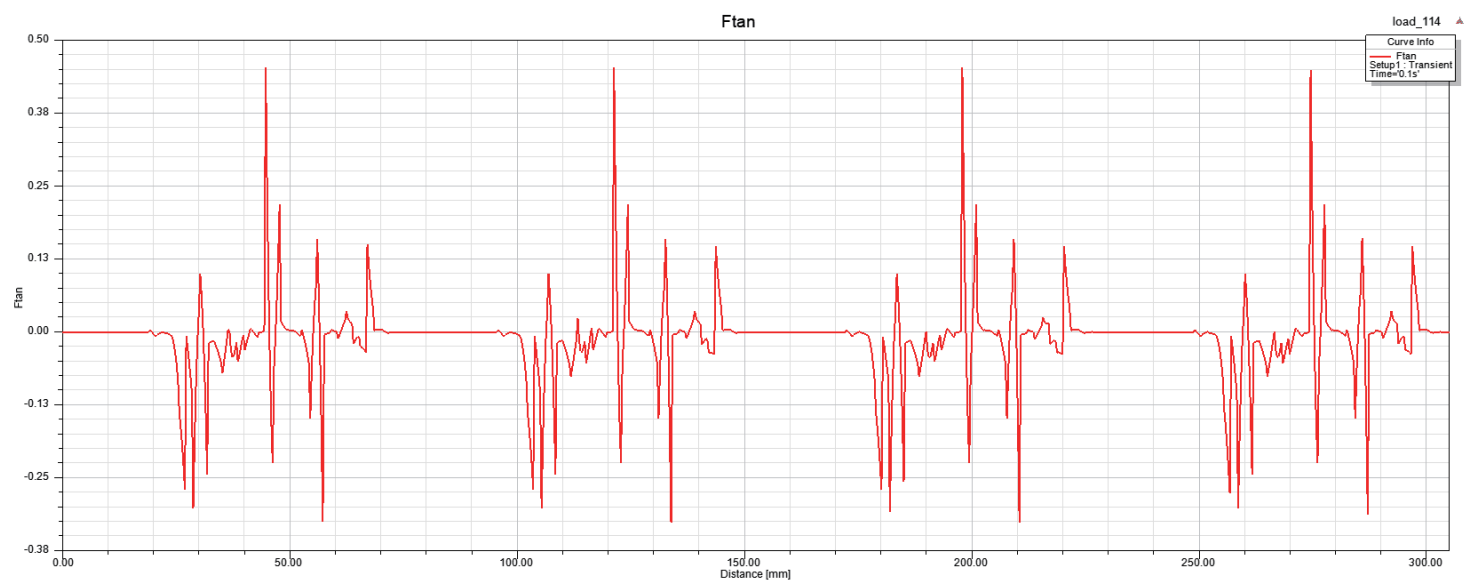

Fig. 4. (Color online) Waveform of tangential electromagnetic force density of synchronous generator. 


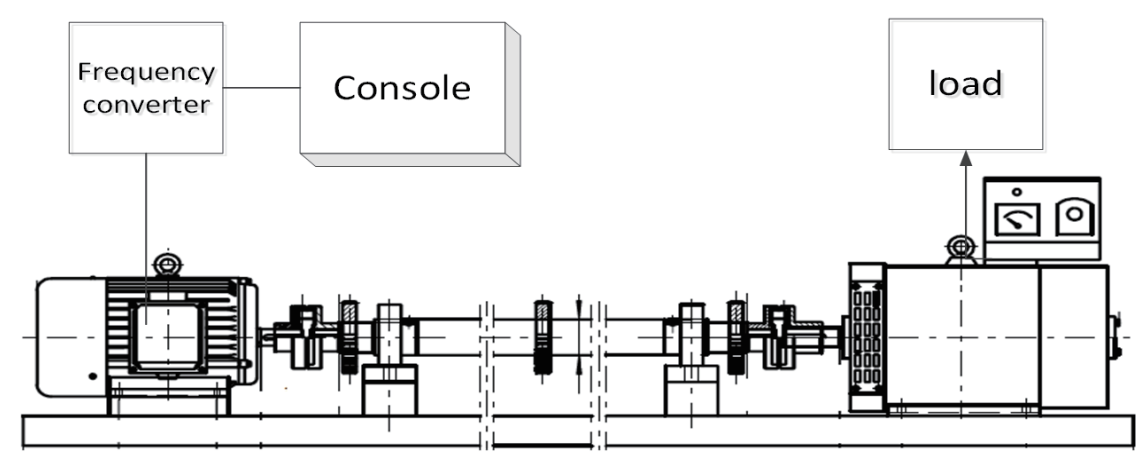

Fig. 5. Composition of the vibration test platform.

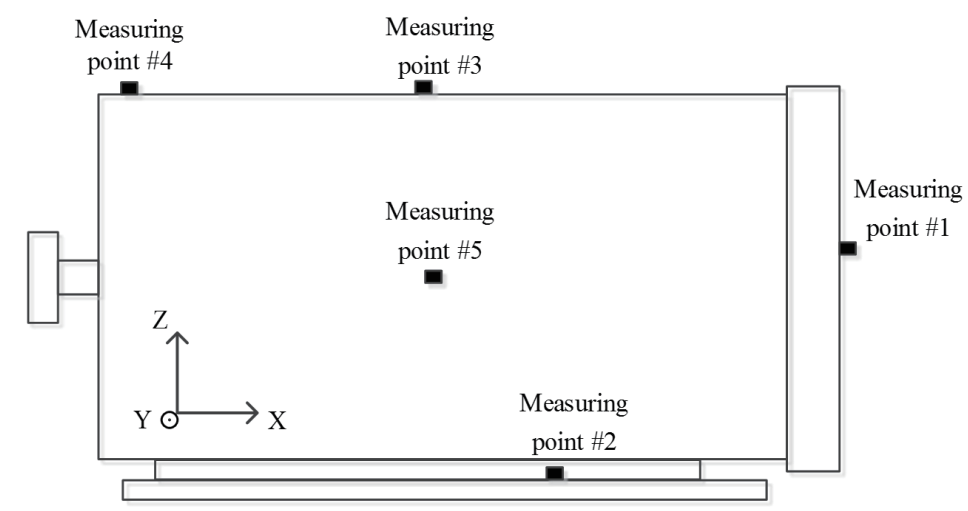

Fig. 6. Layout of vibration measurement points.

resistance load, and speed sensor. In accordance with the vibration test specifications of GB/T 2820.9, GB/T 6075.1, and JB/T 10490, there are five measurement points on the generator body: measurement point $\# 1$ is in the center of the rear cover, $\# 2$ is in the machine foot, \#3 is in the top middle of the front cover, \#4 is in the front of the front cover, and \#5 is on the side of the generator, and the layout is shown in Fig. 6.

\subsection{Experiment on resistive load}

In the experiment, the speed of the generator was $1440 \mathrm{rpm}$. The value of the resistance was adjusted, that is, the active power was changed, and the vibration signals were collected by the instrument. Here, we focused on the vibration amplitude at measurement point $\# 3$ in the $Z$ direction. Table 3 shows vibration amplitude at measurement point \#3 with different powers.

The distribution of the vibration amplitude at measurement point \#3 under different powers is shown in Fig. 7. It can be seen that as the resistive load increases, the generator vibration amplitude increases monotonically.

We performed frequency domain analysis on the vibration measurement data when the generator output power was $512.91 \mathrm{~W}$, and the result is shown in Fig. 8. The vibration amplitude of the generator is considerable at low and medium frequencies, and the vibration is greatest 
Table 3

Vibration amplitude at measurement point \#3.

\begin{tabular}{lccccccc}
\hline Measurement no. & 1 & 2 & 3 & 4 & 5 & 6 & 7 \\
\hline Active power $(\mathrm{W})$ & 0 & 279.58 & 325.18 & 395.94 & 512.91 & 716.65 & 780.96 \\
Vibration amplitude $\left(\mathrm{m} / \mathrm{s}^{2}\right)$ & 2.93000 & 2.90766 & 2.9155 & 2.92628 & 2.94098 & 2.95862 & 2.9694 \\
\hline Measurement No. & 8 & 9 & 10 & 11 & 12 & 13 & 14 \\
\hline Active power $(\mathrm{W})$ & 839.29 & 916.38 & 993.20 & 1108.86 & 1241.46 & 1396.38 & 1623.94 \\
Vibration amplitude $\left(\mathrm{m} / \mathrm{s}^{2}\right)$ & 2.98704 & 3.0184 & 3.06152 & 3.10072 & 3.1213 & 3.15756 & 3.16638 \\
\hline Measurement no. & 15 & 16 & 17 & 18 & & & \\
\hline Active power $(\mathrm{W})$ & 1766.61 & 1902.10 & 2056.52 & 2298.62 & & & \\
Vibration amplitude $\left(\mathrm{m} / \mathrm{s}^{2}\right)$ & 3.17422 & 3.18108 & 3.2144 & 3.23694 & & & \\
\hline
\end{tabular}

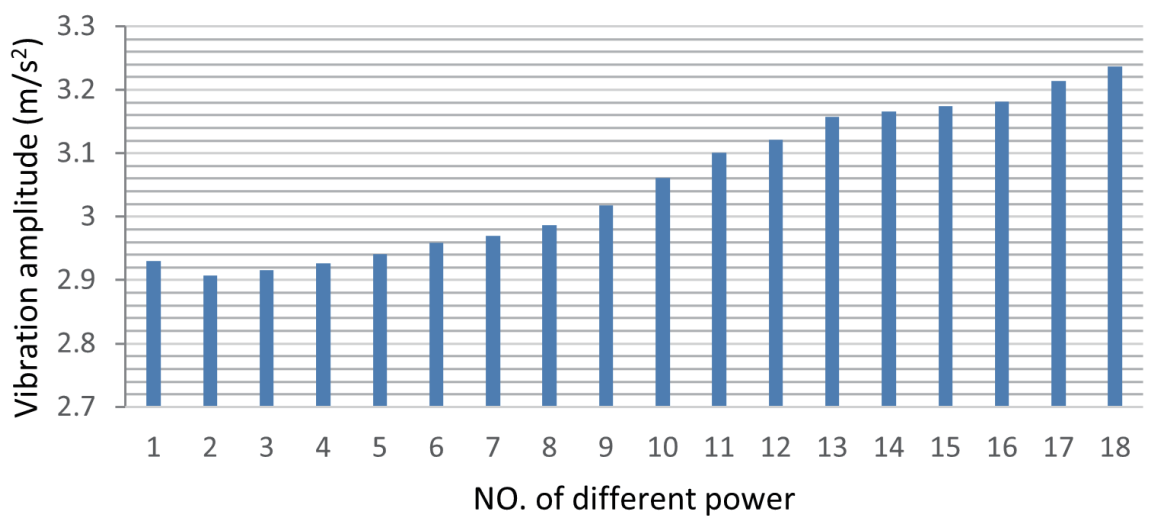

Fig. 7. (Color online) Vibration amplitude of different powers at measurement point \#3.

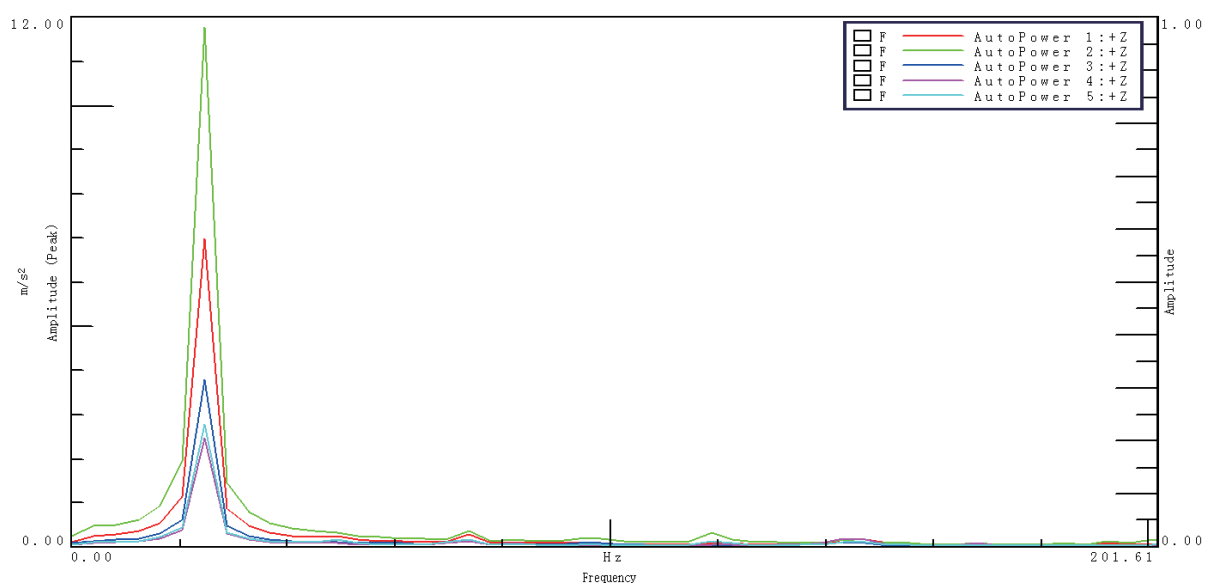

Fig. 8. (Color online) Frequency spectrogram of vibration at five points when power is $512.91 \mathrm{~W}$.

at $24.05 \mathrm{~Hz}$. The analysis shows that this frequency is a multiple of the motor speed, which resonates with the first-order natural frequency of $24.566 \mathrm{~Hz}$ of the experimental platform, and the vibration amplitude is large. 


\subsection{Experiment on resistance inductive load coupling}

In the experiment on a resistive inductive load, the stable rotation speed was $1440 \mathrm{rpm}$, the size of the resistive inductive load was changed, and the value of the active or reactive power was used to represent the resistive inductive load. Measurement point \#3 was selected to analyze the vibration of the motor. Fixing the resistive load, we changed the inductive load and measured the vibration amplitude. We kept the resistive load at $3000 \Omega$, increased the inductive load, and collected and analyzed the measured vibration amplitude at measurement point \#3 to obtain Table 4. As the reactive power increased, the generator vibration response increased.

\section{Data Fitting and Verification}

\subsection{Fitting of vibration data}

The transmission law between the load change and the vibration signal is complex, and it is difficult to obtain it using direct mathematical formulas. In order to predict the amplitude of vibration with load changes, MATLAB software was used to fit the experimental data to obtain the relationship between them. The data fitting involves three variables, resistive load, inductive load, and vibration response, and the surface fitting method was adopted. Among them, the resistive load was set to 18 values from 365 to $3000 \Omega$ and the inductive load was varied from a reactive power of 10 to $3300 \mathrm{~W} .137$ groups of vibration signal data of measurement point \#3 under different powers were selected for the research. Table 5 shows eight groups of vibration amplitude with different powers.

With the data obtained from the vibration test, three methods of fitting were used: a custom equation, interpolation, and polynomial fitting. The goodness of fitting of four groups (custom equation group, interpolation group, and two polynomial groups) is shown in Table 6 .

Comparison of the four sets of fitting parameters showed that R-square and Adj R-Sq are closest to 1 and SSE and RMSE are closest to 0 for Polynomial (2), indicating the best fitting to the experimental data. Most of the data lie on the fitting curve or are evenly distributed on both sides as shown in Fig. 9. The functional formula of the relationship between the resistive load,

Table 4

Vibration amplitude under different loads at measurement point \#3.

\begin{tabular}{lcccccccc}
\hline Reactive power (var) & 29.75 & 57.34 & 103.09 & 172.57 & 305.67 & 453.16 & 734.54 & 1375.47 \\
\hline Vibration amplitude $\left(\mathrm{m} / \mathrm{s}^{2}\right)$ & 2.9086 & 2.9155 & 2.9263 & 2.9410 & 2.9851 & 3.0321 & 3.0723 & 3.1056 \\
\hline Reactive power $(\mathrm{var})$ & 1903.69 & 2635.12 & 3184.85 & & & & & \\
\hline Vibration amplitude $\left(\mathrm{m} / \mathrm{s}^{2}\right)$ & 3.1350 & 3.2007 & 3.2203 & & & & & \\
\hline
\end{tabular}

Table 5

Vibration amplitude of measurement point \#3 with different powers.

\begin{tabular}{lcccccccc}
\hline Active power $(\mathrm{W})$ & 3942.26 & 3515.01 & 3140.60 & 2668.87 & 2383.56 & 2107.51 & 1841.64 & 1703.98 \\
Reactive power $($ var $)$ & 2680.73 & 2214.45 & 1852.95 & 1414.50 & 1167.94 & 927.31 & 718.24 & 562.31 \\
Vibration amplitude $\left(\mathrm{m} / \mathrm{s}^{2}\right)$ & 3.2879 & 3.2977 & 3.2761 & 3.2644 & 3.2497 & 3.2075 & 3.1683 & 3.1458 \\
\hline
\end{tabular}


Table 6

Goodness of data fitting.

\begin{tabular}{lcccc}
\hline & SSE & R-square & Adj R-Sq & RMSE \\
\hline Custom equation & 0.9399 & 0.4854 & 0.4625 & 0.1022 \\
Interpolation & $2.367 \mathrm{e}-30$ & 1 & - & - \\
Polynomial (1) & 0.1959 & 0.8928 & 0.888 & 0.04665 \\
Polynomial (2) & 0.1809 & 0.9009 & 0.8954 & 0.04509 \\
\hline
\end{tabular}

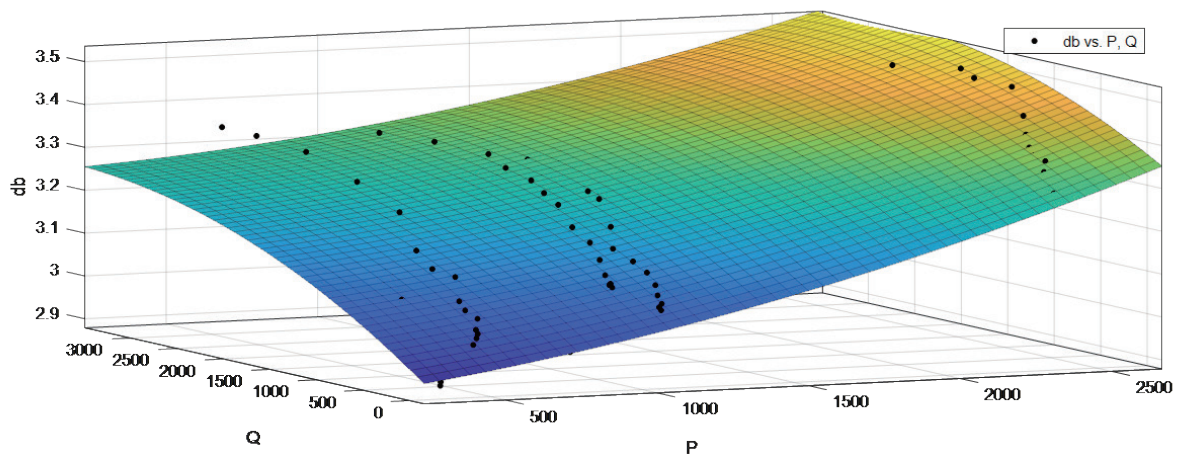

Fig. 9. (Color online) Diagram showing polynomial approximation fitting.

inductive load, and generator vibration response is thus

$$
f(x, y)=p_{00}+p_{10} x+p_{01} y+p_{20} x^{2}+p_{11} x y+p_{02} y^{2} .
$$

Here, $p_{00}=2.932, p_{10}=7.976 \times 10^{-5}, p_{01}=1.656 \times 10^{-4}, p_{20}=3.198 \times 10^{-8}, p_{11}=-1.583 \times 10^{-8}$, and $p_{02}=-2.155 \times 10^{-8}$.

\subsection{Verification of data fitting}

After fitting, we performed the experiment again with different loads and compared the experimental results with the calculation results obtained with the fitting formula, as shown in Table 7. The error was within 5\%, which is within the acceptable range.

\subsection{Comparison with similar studies}

We showed that the vibration response of a generator is affected by its external load type and size. Compared with other similar research, the novelty of this paper is that theoretical analysis, modeling and simulation, and an experiment with acceleration sensors are performed to study the coupling mechanism between the load change and vibration of the generator to provide a theoretical basis for reducing the vibration of a ship generator. Table 8 gives a comparison of the content covered in this study and previous studies. 
Table 7

Vibration amplitude of measurement point \#3 with different powers.

\begin{tabular}{lcccccccc}
\hline Active power $(\mathrm{W})$ & 466.83 & 486.83 & 604.90 & 1205.26 & 1466.55 & 1500.55 & 1824.28 & 1860.41 \\
Reactive power (Var) & 96.27 & 100.17 & 636.57 & 1267.94 & 1764.45 & 1814.45 & 934.11 & 953.21 \\
$\begin{array}{l}\text { Experimental } \\
\text { amplitude }\left(\mathrm{m} / \mathrm{s}^{2}\right)\end{array}$ & 3.0153 & 3.0173 & 3.2133 & 3.2697 & 3.2931 & 3.2967 & 3.2414 & 3.2464 \\
$\begin{array}{l}\text { Calculated } \\
\text { amplitude }\left(\mathrm{m} / \mathrm{s}^{2}\right)\end{array}$ & 2.8999 & 2.9017 & 3.0633 & 3.3225 & 3.3491 & 3.4563 & 3.3128 & 3.3135 \\
Error $(\%)$ & 3.8 & 3.8 & 4.6 & 1.6 & 1.7 & 4.8 & 2.2 & 1.5 \\
\hline
\end{tabular}

Table 8

Comparison with other similar studies.

\begin{tabular}{lccc}
\hline Reference & $\begin{array}{c}\text { Theoretical } \\
\text { analysis }\end{array}$ & $\begin{array}{c}\text { Modeling } \\
\text { simulation }\end{array}$ & $\begin{array}{c}\text { Experiment with } \\
\text { acceleration sensors }\end{array}$ \\
\hline$(2)$ & No & Yes & No \\
$(3)$ & No & No & Yes \\
$(4)$ & Yes & No & No \\
$(5-7)$ & No & No & Yes \\
$(8)$ & Yes & Yes & No \\
$(9-11)$ & Yes & No & No \\
Our research & Yes & Yes & Yes \\
\hline
\end{tabular}

\section{Conclusion}

In this paper, the coupling effect of the resistance and inductive load on the vibration of a ship generator was studied. Through finite element analysis of the electromagnetic force of the generator, a vibration test, experimental data obtained from acceleration sensors, and data fitting, it was concluded that the vibration response of a generator will be affected by its type and size of the external load. Under pure resistive working conditions, the generator vibration response increases with the active power; under resistive inductive load conditions, the generator vibration response increases with the reactive power. Through the results of fitting the experimental data, the generator vibration amplitude can be predicted more accurately.

\section{References}

1 S. Chenet, H. Javadi, Y. Lefevre, and S. Astier: IEEE Trans. Magnet. 31 (1995) 1837. https://doi.org/10.1007/ s00170-017-0819-7

2 W. Su, Y. J. Guo, Z. Z. Su, and F. Q. Meng: Appl. Motor. Cont. 45 (2018) 69. http://en.cnki.com.cn/Article_en/ CJFDTotal-ZXXD201801013.htm

3 X. B. Zhang, D. Wang, T. P. Gu, and D. Z. Liu: Vibrat. Shock. 35 (2016) 195. http://en.cnki.com.cn/Article_en/ CJFDTotal-ZDCJ201602033.htm

4 X. Z. Liu, X. L. Wei, and X. T. Zhang: Micromotor 50 (2017) 68. http://www.cqvip.com/ QK/90482X/201704/672002204.html

5 A. J. Ellison and C. J. Moore: Elec. Eng. Proc. 115 (1968) 11. https://doi.org/10.1049/piee.1968.0284

6 R. J. Brozek: IEEE Trans. Ind. Appl. 2 (1973) 184. https://doi.org/10.1109/TIA.1973.349952

7 F. Kako: IEEE Trans. Power. Apparat. Syst. 102 (1983) 2805. https://doi.org/10.1109/TPAS.1983.317964

8 S. L. Huang, W. N. Yu, H. L. Li, Z. B. Yin, and L. J. Guo. Jour. Jimei. Uni. Natur. Sci. 23 (2018) 455. https:// doi.org/CNKI:SUN:JMXZ.0.2018-06-009 
9 S. H. Lee, J. P. Hong, and S. M. Hwang: IEEE Trans. Ind. Appl. 45 (2009) 1954. https://doi.org/10.1109/ TIA.2009.2031905

10 S. Rainer, O. Biro, and B. Weilharter: IEEE Trans. Mag. 46 (2010) 2807. https://doi.org/10.1109/ TMAG.2010.2043827

11 M. Boesing, T. Schoenen, and K. A. Kasper: IEEE Trans. Mag. 46 (2010) 2986. https://doi.org/10.1109/ TMAG.2010.2042291

\section{About the Authors}

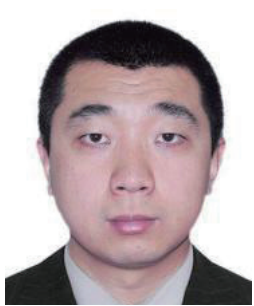

Hanlin Li is a lecturer at Jimei University. He received his B.S. and M.S. degrees, both in marine engineering, from Jimei University in 2004 and 2007, respectively. He is currently a Ph.D. candidate. His current research interests include vibration and noise control in marine engineering.

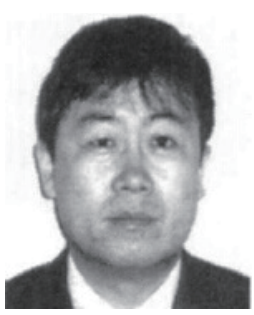

Hongliang Yu received his Ph.D. degree in 2002 from Kobe University of Mercantile Marine, Japan. He is now a professor at Jimei University, Xiamen, China. His major research interests include modern marine engineering management, vibration fault diagnosis, module shipbuilding, and reliability.

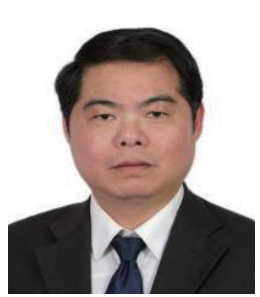

Wanneng Yu has been a professor at Jimei University, China, since 2014. $\mathrm{He}$ earned his $\mathrm{Ph} . \mathrm{D}$. degree in power electronics and electric driving from Shanghai Maritime University in 2010. His research interests are in the areas of integrated electric propulsion systems and intelligent control of ships. (wnyu2007@jmu.edu.cn)

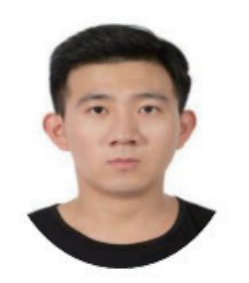

Shilun Huang is a postgraduate student at Jimei University. He received his B.S. degree in port, waterway, and coastal engineering from Dalian Ocean University in 2017. His current research interests include vibration and noise control in marine engineering.

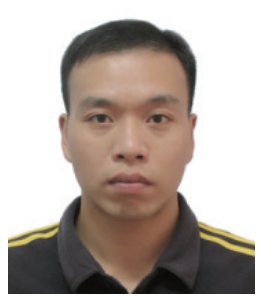

Jianbin Liao is a vice-professor of Jimei University. He received his B.S. and M.S. degrees, both in marine engineering, from Jimei University in 1998 and 2007, respectively, and is currently a Ph.D. candidate at Dalian Maritime University. His current research interests include marine engineering and fault diagnosis. 


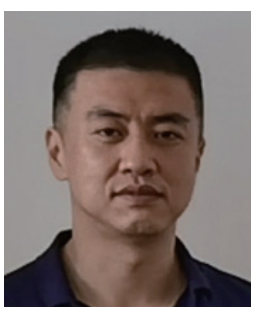

Jin Yan is a vice-professor of Jimei University. He received his M.S. and $\mathrm{Ph}$.D. degrees, both in marine engineering, from Dalian Maritime University in 2006 and 2013, respectively. His current research interests include vibration and noise control and fault diagnosis.

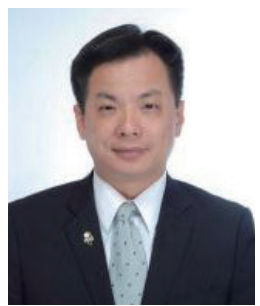

Chih-Cheng Chen has been a professor at Jimei University, China, since 2017. He became a member of IEEE in 2011 and a senior member in 2016. He earned his M.S. and Ph.D. degrees from the Department of Mechatronics Engineering, National Changhua University of Education. He has been studying RFID applications in various fields of industry. His research interests include AIoT technology and RFID applications.

(201761000018@jmu.edu.cn) 